\title{
Dynamic Changes in Starch Metabolism and Endogenous Hormones during Stolon Formation in Tulipa edulis
}

\author{
Yuanyuan Miao, Qiaosheng Guo, Zaibiao Zhu', Xiaohua Yang, Changlin Wang, Yuan Sun, \\ and Li Liu \\ Institute of Chinese Medicinal Materials, Nanjing Agricultural University, Nanjing 210095, People's \\ Republic of China
}

\begin{abstract}
AdDitional INDEX wORDs. medicinal plant, organogenesis, carbon metabolism, development characteristics
Abstract. The stolon is the main asexual reproductive organ of the medicinal plant Tulipa edulis and has special morphology. In the greenhouse experiment presented herein, the dynamic changes in carbohydrates and related enzymes, proteins, and endogenous hormones of stolons during $T$. edulis stolon formation were investigated. The results showed that the content of total soluble sugar, sucrose, reducing sugar, fructose, and starch were all significantly enhanced in the middle period when stolon emerged and maintained at relatively high levels until the later period of stolon formation, while protein content decreased during stolon formation. The activities of amylase (AMY), sucrose phosphate synthase (SPS), and sucrose synthase (SS) peaked in the initial period and were negatively correlated with soluble sugars. However, adenosine diphosphoglucose pyrophosphorylase (AGPase) activity increased as stolon formation progressed, and the changes in soluble starch synthase (SSS), granule-bound starch synthase (GBSS) activities presented a single peak, reaching their maximums in the middle period. AGPase, SSS, and GBSS activities were all positively related to starch content. Moreover, quantitative real-time polymerase chain reaction (qRT-PCR) verified the changes in SS and SSS activities via the expression levels of the SS, SSSI, and SSSII genes. The gibberellin (GA) and zeatin riboside (ZR) content attained their maximum in the initial period of stolon formation. Indole-3-acetic acid (IAA) and abscisic acid (ABA) remained at high levels during the initial and middle period and decreased significantly during the later period of stolon formation, inversely to the ratio of ABA:IAA. Analysis of the physiological changes in T. edulis stolon indicated that the accumulation of soluble sugars and starch via various enzymes, a high level of IAA and a low ABA to IAA ratio mainly contributed to stolon development of T. edulis. This paper explored carbohydrate levels and endogenous hormones profiles during stolon formation, which provided the theory basis for further regulating stolon growth of $T$. edulis.
\end{abstract}

Tulipa edulis is a perennial herb of the genus Tulipa within the Liliaceae and is commonly distributed in the eastern provinces and regions of China, particularly growing on sunny hills, under sparse forest, or along riverbanks. It is also distributed in Japan and Korea. The dried bulb of T. edulis without tomentose tunic, Guangcigu, is currently an important medicine for the treatment of a variety of cancers, such as throat cancer, lymphoma, and breast cancer (Chinese Herbalism Editorial Board, 1999). Because of its medicinal value and industrial importance, the demand for Guangcigu has increased steadily in recent years, and the wild sources of $T$. edulis are, therefore, being reduced to a greater extent due to overexploitation (Bing et al., 2008; Miao et al., 2015).

The stolon is one of the main asexual reproductive organs of T. edulis and has unique morphology. It is similar to a rhizome in appearance, but it has no visible node, internode, or adventitious roots (ARs). It bulges outward and extends farther, to more than $10 \mathrm{~cm}$ at the bottom of the stem. The stolon is pushed deep into the soil or culture medium and develops a bulblet at the tip (Fig. 1A and B). Finally, the stolon shrivels up, and the bulblet, surrounded by a thin brown tunic, is left (Custers et al., 1992; Miao et al., 2015). The stolon plus the bulblet is called the dropper (Custers et al., 1992). The stolon

Received for publication 25 Sept. 2015. Accepted for publication 14 Jan. 2016. This work was supported by the National Natural Science Foundation of China (81202867).

${ }^{1}$ Corresponding author. E-mail: zhuzaibiao@njau.edu.cn. has been described in micropropagation culture in some Tulipa sp. plants as a transitional stage of bulblet formation (Custers et al., 1992; Koster, 1993). Nevertheless, few literature reports referred to the similar organ under natural conditions. Stolon formation in tulip (Tulipa gesneriana) has been observed in seedlings and small bulbs as well as in large bulbs, which grow in wet soil (Le Nard and De Hertogh, 1993). The number of stolons markedly influences the reproductive index. In addition to its role as a reproductive organ, the stolon of T. edulis is assumed to play an important role in its adaptation to diverse conditions. Therefore, it is necessary to explore the mechanisms involved in the formation of the stolon in T. edulis so that production can be improved to meet the high market demands.

Stolon formation is a process of organogenesis, which is defined as growth with an irreversible increase in size involving changes in morphology or anatomy at the intracellular or tissue level (Sinnott, 1960). Organogenesis, such as the initiation of an AR, lateral root (LR), stolon, or rhizome, should be considered to be a complex multistep process characterized by both cell division and cell enlargement, which are affected by endogenous hormones and nutritional factors with carbohydrates playing a central role (Mcintyre, 2001; Xu et al., 1998a, 1998b).

Studies of the influence of nutrition on organogenesis have shown that the relative amounts of carbohydrates can determine the path of bud development into a shoot or rhizome (Mcintyre, 2001). It was observed that once carbohydrate reserves were partly replenished and abundant, the growth of new rhizomes 

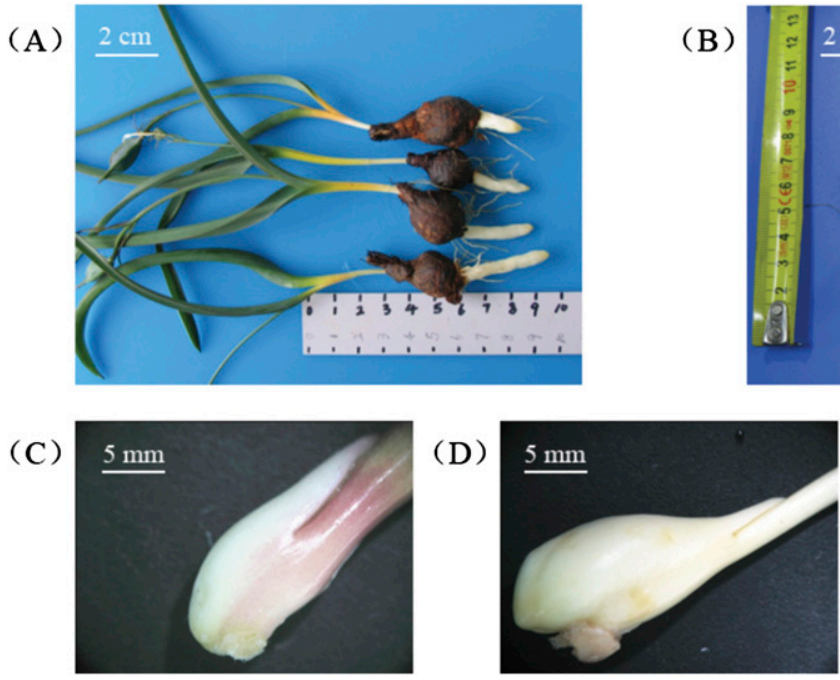

(E)

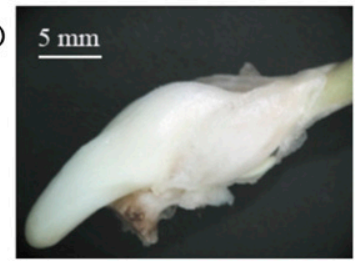

Fig. 1. (A) Tulipa edulis with elongated stolon; (B) T. edulis stolon developed into a new bulb; and (C, D, and E) T. edulis stolon formation at the initial, middle, and later stages.

was initiated (Gauci et al., 2009). The allocation and fluxes of carbohydrates in the cutting apparently play an important role in AR formation, as suggested by the fact that earlier stages of AR formation in plants are limited by carbohydrate availability, especially that of sucrose in the leaves (Klopotek et al., 2010; Rapaka et al., 2005). In addition, sugar is also likely to be an important determinant of LR formation and the tuberization process (Macgregor et al., 2008; Mitprasat et al., 2011). Fernie and Willmitzer (2001) have testified that soluble carbohydrates, especially sucrose, have been considered to be strong inducers of the formation of underground storage organs. Enhancing the level of sucrose in the stolon increases the number of initiated tubers (Jackson, 1999) and is helpful in the rhizome formation of Nelumbo nucifera (Cheng et al., 2013a) and the corm formation of Sagittaria trifolia (Cheng et al., 2013b). Similarly, Takahashi et al. (2003) previously showed that AR formation is stimulated by sucrose. Sucrose is translocated to the stem base to be cleaved into hexoses, which are used directly as a carbon source or converted into starch for storage (Ahkami et al., 2009). Moreover, sucrose can be taken up and metabolized, increasing LR formation emergence via a specific mechanism (Macgregor et al., 2008). In potato (Solanum tuberosum) tubers, a small fraction of starch is converted into the reducing sugars, glucose and fructose, to provide carbon skeletons and energy (Schreiber et al., 2014). Nevertheless, it is not too surprising that for a long time, starch formation was another parameter discussed as a requirement for tuber initiation and enlargement (Fernie and Willmitzer, 2001). The key enzyme involved in starch degradation is AMY, which decomposes starch into soluble sugars to maintain proper growth in plants (Mishra and Dubey, 2013). Among sucrose-metabolizing enzymes, SPS catalyzes the biosynthesis of sucrose and is regarded as a major control point in sucrose biosynthesis and its partitioning, utilization, mobilization, and cellular function in plants (Huber and Huber, 1996), whereas SS and invertase are involved in the cleavage of sucrose (Verma et al., 2012). Moreover, in starchstoring sinks, incoming sucrose is predominantly degraded via the SS pathway (Sung et al., 1989). Baroja-Fernández et al. (2009) showed that the enhancement of SS activity represents a useful strategy for increasing starch accumulation and yield in potato tubers. The synthesis of starch requires the main participation of various enzymes including AGPase, SSS, and GBSS (Geigenberger, 2003; Mukerjea et al., 2010). Both adenosine diphosphate glucose (ADPG) synthesizing SS and AGPase activity patterns were found to correlate well with the amount of ADPG and starch content in plants (Baroja-Fernández et al., 2003). Cheng et al. (2013a, $2013 b)$ discovered that a gene encoding GBSS enhanced messenger RNA (mRNA) levels during rhizome and corm development in starch synthesis.

The plant hormones auxin and cytokinin are central endogenous signaling molecules that positively and negatively regulate AR organogenesis, respectively (AgullóAntón et al., 2014; Della Rovere et al., 2013), as observed in LR formation (Bielach et al., 2012; Ivanchenko et al., 2008). In addition, ABA is consistently thought to inhibit AR and LR induction (da Costa et al., 2013; Guo et al., 2012). In the rhizome and stolon, phytohormones such as IAA and GA are involved in the rhizome development signaling pathway, and auxin/IAA appears to act as a negative regulator of rhizome development, whereas GA acts as the activator of rhizome development (Hu et al., 2011). Xu et al. (1998b) observed that a high GA content promotes stolon elongation and inhibits storage organ (tuber) formation. In terms of bulbing ability in bulbous plants, Rice et al. (1983) enhanced tulip bulb production in vitro by soaking adventitious shoots developed into a bulb in $\mathrm{GA}_{3}$. In contrast, treatments with $\mathrm{GA}_{3}$ in explant shoots strongly inhibited the bulb formation of tulips in a study reported by Podwyszyńska and Ross (2003), and the application of inhibitors of GA biosynthesis, such as paclobutrazol, had a positive effect on bulb formation in initial explants of some bulbous plants including Leucojum aestivum (Ptak, 2014) and tulip (Podwyszyńska, 2006). ABA was found to stimulate the formation of bulb in Hyacinthus orientalis (Li et al., 2002). However, Podwyszyńska and Ross (2003) claimed that ABA has an adverse effect on tulip bulb formation, which was confirmed by demonstration that the formation of bulblets was hampered by ABA, particularly at higher concentrations, in the tarda tulip [Tulipa tarda (Maślanka and Bach, 2014)]. Numerous studies have reported that auxin exerts stimulatory effects on in vitro bulb formation. Podwyszyńska (2006) found that auxins promoted the efficiency of tulip bulb formation, and bulbing in lily (Lilium) depended on the presence of exogenous auxins, mainly naphthalene acetic acid [NAA (Van Aartrijk and Blom-Barnhoorn, 1981)]. There are conflicting indications regarding the roles of cytokinins in bulb formation in vitro. Exogenous benzyladenine stimulated bulb development in Urginea maritima (El Grari and Backhaus, 1987) but inhibited bulb formation in Narcissus jonquilla (Chow et al., 1992). The use of media with 6-benzyl-aminopurine promoted bulbing capacity together with NAA in bulb scale cultures of Lilium ledebourii (Bakhshaie et al., 2010) and Muscari azureum (Uranbey et al., 2010). 
To the best of our knowledge, the development characteristics and formation process of the $T$. edulis stolon remain unknown. It would be highly significant to investigate the formation mechanism of the stolon for efficient cultivation. Thus, the aims of this study were 1) to investigate changes in carbohydrate content and related enzyme activities as well as protein and endogenous hormone content during stolon formation in T. edulis and 2) to clarify the relationships among nutrition, related enzymes, and endogenous hormones in response to stolon formation and to further elucidate the possible mechanism of stolon formation. For these purposes, nutrient (i.e., total soluble sugar, sucrose, reducing sugar, fructose, starch, and protein) content, the activities of related enzymes (i.e., SS, SPS, AMY, AGPase, SSS, and GBSS), and the content of endogenous hormones (viz. GA, IAA, ABA, and ZR) were measured at the location where the stolon of $T$. edulis formed.

\section{Materials and Methods}

Plant material and growth conditions. The experiment was performed under natural day/night conditions in the greenhouse of the Institute of Chinese Medicinal Materials at Nanjing Agricultural University, Nanjing, People's Republic of China. Tulipa edulis bulbs were obtained from Funan county, Anhui Province in Sept. 2013. Disease-free bulbs of uniform size $(\approx 1.0 \mathrm{~g})$ were selected for planting in polyethylene plastic pots (42 cm length, $42 \mathrm{~cm}$ width, and $5.5 \mathrm{~cm}$ depth) filled with taupe sandy loam. The gravimetric water content of taupe sandy loam at field capacity (FC) was $26.56 \%$. The water content of the taupe sandy loam was adjusted gravimetrically every other day to $80 \%$ FC. The pots were arranged following a completely randomized block design. On the basis of the previous research, the process of stolon formation can be divided into the following three stages: 1) T1, the initial period of stolon formation, $41 \mathrm{~d}$ after planting (DAP; Fig. 1C); 2) T2, the middle period of stolon formation, 118 DAP (Fig. 1D); and 3) T3, the later period of stolon formation, 133 DAP (Fig. 1E). Fresh samples of stolons from these three stages were collected at the appropriate time and immediately frozen in liquid nitrogen after their fresh weight had been determined and then stored at $-80{ }^{\circ} \mathrm{C}$ until analysis.

Determination of CARbohydrate content. Carbohydrate content was determined colorimetrically, essentially as described earlier (Mishra and Dubey, 2013; Xia et al., 2005). Briefly, $\approx 0.5 \mathrm{~g}$ frozen samples were homogenized with $4 \mathrm{~mL}$ $80 \%$ ethanol and extracted at $80{ }^{\circ} \mathrm{C}$ for $30 \mathrm{~min}$, then centrifuged at $8000 g_{n}$ for $20 \mathrm{~min}$. Samples were extracted thrice, and the supernatants were decolorized by activated carbon at $80^{\circ} \mathrm{C}$ for $30 \mathrm{~min}$ and then diluted to $25 \mathrm{~mL}$ with water. After filtration, extracts were used for the measurement of soluble sugars including sucrose, reducing sugar, and fructose. For starch extraction, the precipitates left in the centrifuge tubes after sugar extraction were added $2 \mathrm{~mL}$ of water and then placed in boiling water bath for $15 \mathrm{~min}$. After cooling, $2 \mathrm{~mL}$ of $9.2 \mathrm{M}$ perchloric acid was added, and contents were stirred for $15 \mathrm{~min}$ and volumes were made up to $10 \mathrm{~mL}$ with water. Supernatants were collected after centrifuging the contents at $5000 g_{\mathrm{n}}$ for $15 \mathrm{~min}$. Residues were reextracted with $2 \mathrm{~mL}$ of $4.6 \mathrm{~m}$ perchloric acid. After centrifugation, all perchloric acid-containing supernatants were pooled and volumes were made up to $100 \mathrm{~mL}$ with water for starch content measurement. Total soluble sugar and starch concentrations were measured following the method of the anthrone reaction, and the absorbance was recorded at $630 \mathrm{~nm}$. The content of reducing sugar was determined using 3,5-dinitrosalicylic acid with the absorbance at $540 \mathrm{~nm}$. The sucrose and fructose contents were determined using hydrolysis and resorcinol reactions, and the absorbance was measured at $480 \mathrm{~nm}$.

AsSAy to DETERmine Protein CONTENT AND AMY ACTIVITY. Samples of $\approx 0.25 \mathrm{~g}$ in weight were ground and extracted with $8 \mathrm{~mL}$ distilled water at $4{ }^{\circ} \mathrm{C}$ to separate a soluble fraction. The supernatant was taken after centrifugation at $4{ }^{\circ} \mathrm{C}$ and $8000 g_{\mathrm{n}}$ for $15 \mathrm{~min}$ and used for the measurement of soluble protein content and AMY activity. The precipitates were extracted with $3 \mathrm{~mL}$ of $1 \mathrm{M} \mathrm{NaOH}$ at $90^{\circ} \mathrm{C}$ for $20 \mathrm{~min}$, and then centrifuged to obtain the supernatant for the determination of the insoluble protein content. The soluble and insoluble protein contents were measured according to Bradford (1976), using the method of coomassie brilliant blue G-250 with bovine serum albumin as a standard. AMY activity was measured using a test kit (C016; Nanjing Jiancheng Bioengineering Institute, Nanjing, China). The assay depends on unhydrolyzed starch, which turns blue in the presence of iodine, with absorbance at $660 \mathrm{~nm}$ when an excess of substrate starch is added to the reaction, based on the theory that starch can be hydrolyzed by AMY. AMY activity was measured based on the amount of hydrolyzed starch as determined by the shades of blue. One unit of enzyme activity was defined as the quantity of AMY required to hydrolyze $10 \mathrm{mg}$ starch, and the enzyme activity was expressed as units per gram fresh weight. The reaction was conducted at $37^{\circ} \mathrm{C}$ for $15 \mathrm{~min}$.

Sucrose Metabolism-RELATEd ENZYMes ASSAY. Test kits (A097, A098; Nanjing Jiancheng Bioengineering Institute) were employed for the assays of SS and SPS activities. $0.1 \mathrm{~g}$ of frozen sample was ground and extracted with $0.9 \mathrm{~mL}$ extracting solution [100 mM Tris- $\mathrm{HCl}, \mathrm{pH} 7.0,10 \mathrm{~mm} \mathrm{MgCl}_{2}$, $2 \mathrm{~mm}$ ethylenediaminetetraacetic acid (EDTA), $20 \mathrm{~mm}$ dithiothreitol (DTT), and $0.1 \%$ Triton X-100] in ice bath condition and centrifuged at $4000 \mathrm{~g}_{\mathrm{n}}$ for $15 \mathrm{~min}$ at $4{ }^{\circ} \mathrm{C}$. The supernatant was used for SS and SPS activity assays with the instruction of test kits. The reaction mixture containing supernatant $(30 \mu \mathrm{L})$, buffer $(150 \mu \mathrm{L} 50 \mathrm{~mm}$ Tris-HCl, pH 7.0), promoter $(2 \mu \mathrm{L} 0.75 \mathrm{M}$ $\mathrm{MgCl}_{2}$ ), and substrate $[2 \mu \mathrm{L} 0.225 \mathrm{M}$ uridine diphosphate glucose (UDPG), $3 \mu \mathrm{L} 0.5 \mathrm{~m}$ fructose for SS; $2 \mu \mathrm{L} 0.225 \mathrm{~m}$ UDPG, $3 \mu \mathrm{L} 0.5 \mathrm{~m}$ fructose-6- phosphate for SPS] was incubated in $37{ }^{\circ} \mathrm{C}$ for $30 \mathrm{~min}$, and hydrolysate $(2 \mathrm{~mL} 0.05 \mathrm{M}$ $\mathrm{NaOH}$ ) was added to reaction system for mixing to place in the boiling water bath for $8 \mathrm{~min}$. The absorbance was recorded at $290 \mathrm{~nm}$ when the mixture cooled to room temperature. The activity of SS or SPS was expressed in terms of micromoles of sucrose per gram fresh weight per minute.

Measurement OF THE KEY ENZYMES OF STARCH SYNTHESIS. The extraction and determination procedures for AGPase, SSS, and GBSS were according to Nakamura et al. (1989) with a slight modification. Briefly, $0.1 \mathrm{~g}$ sample was homogenized with a pestle in a precooled mortar that contained $1 \mathrm{~mL}$ precooled extraction medium: $100 \mathrm{~mm}$ hydroxyethyl piperazine ethanesulfonic acid (HEPES)-NaOH (pH 7.6), $8 \mathrm{~mm} \mathrm{MgCl}_{2}$, $5 \mathrm{~mm}$ DTT, $2 \mathrm{~mm}$ EDTA, 12.5\% (v/v) glycerol, 5\% (w/v) polyvinylpyrrolidone 40 , and $50 \mathrm{~mm} 2$-mercaptoethanol. The homogenate was centrifuged at $10,000 \mathrm{~g}_{\mathrm{n}}$ for $10 \mathrm{~min}$ at $4{ }^{\circ} \mathrm{C}$, and the supernatant was used for AGPase and SSS assays. The precipitate was suspended in the above extraction medium for GBSS activity measurement.

AGPase activity was assayed as follows: $20 \mu \mathrm{L}$ of supernatant was combined with $260 \mu \mathrm{L}$ of a reaction mixture containing 
$100 \mathrm{~mm}$ HEPES-NaOH (pH 7.5), $1.2 \mathrm{~mm}$ ADPG, 3 mм pyrophosphoric acid (PPi), $5 \mathrm{~mm} \mathrm{MgCl}_{2}$, and $4 \mathrm{~mm}$ DTT, and the mixture was incubated at $30{ }^{\circ} \mathrm{C}$ for $20 \mathrm{~min}$, then placed in a boiling water bath for $1 \mathrm{~min}$ and cooled to room temperature. The mixture was centrifuged at $10,000 \mathrm{~g}_{\mathrm{n}}$ for $10 \mathrm{~min}$, and 240 $\mu \mathrm{L}$ of supernatant was mixed with $100 \mu \mathrm{L} 10 \mathrm{~mm}$ nicotinamide adenine dinucleotide phosphate (NADP). Then, $10 \mu \mathrm{L} 0.4$ unit phosphoglucomutase and $10 \mu \mathrm{L} 0.4$ unit glucose-6-phosphate dehydrogenase were added to the reaction solution and mixed, and the increase in absorbance at $340 \mathrm{~nm}$ in 2 min was recorded. One unit of AGPase was defined as the quantity of enzyme needed to produce $1 \mu \mathrm{mol}$ dihydronicotinamide adenine dinucleotide phosphate (NADPH), and the enzyme activity was expressed as micromoles per gram fresh weight per minute.

The supernatant and suspension described above were used for the SSS and GBSS activity assays, respectively. The assay of SSS activity was consistent with GBSS, using the method of Nakamura et al. (1989) with a slight modification. Briefly, $150 \mu \mathrm{L}$ sample solution was mixed with $270 \mu \mathrm{L}$ of $50 \mathrm{~mm}$ HEPES-NaOH buffer (pH 7.4) including 1.6 mm ADPG, $1.8 \mathrm{mg}$ amylopectin and $15 \mathrm{~mm}$ DDT, and then the mixture was incubated at $30{ }^{\circ} \mathrm{C}$ for $20 \mathrm{~min}$ and afterward placed in boiling water for $1 \mathrm{~min}$. The mixture was cooled rapidly in an ice bath, and then $150 \mu \mathrm{L}$ of $50 \mathrm{~mm}$ HEPES-NaOH buffer $(\mathrm{pH} \mathrm{7.4)}$ containing $5 \mathrm{~mm}$ phosphoenolpyruvate, $200 \mathrm{mM} \mathrm{KCl}, 10 \mathrm{~mm}$ $\mathrm{MgCl}_{2}$, and 1.5 unit pyruvate kinase were added, and the mixture was incubated at $30{ }^{\circ} \mathrm{C}$ for $30 \mathrm{~min}$. The reaction mixture was then placed in a boiling water bath for $1 \mathrm{~min}$ and centrifuged at $10,000 g_{n}$ for 5 min after cooling. Next, $450 \mu \mathrm{L}$ of supernatant was mixed with $300 \mu \mathrm{L} 50 \mathrm{~mm}$ HEPES-NaOH buffer ( $\mathrm{pH} 7.4$ ) including $10 \mathrm{~mm}$ glucose, $20 \mathrm{~mm} \mathrm{MgCl}_{2}$, and $2 \mathrm{mmol} \cdot \mathrm{L}^{-1} \mathrm{NADP}$. Then, $10 \mu \mathrm{L} 2.8$ unit hexokinase and $10 \mu \mathrm{L}$ 0.7 unit glucose-6-phosphate dehydrogenase were successively added to the above mixture and vigorously shaken immediately, and the change in absorbance at $340 \mathrm{~nm}$ in 2 min was measured. One unit of enzyme activity was expressed as micromoles per gram fresh weight per minute.

DETERMINATION OF ENDOGENOUS HORMONES. The extraction, purification, and determination of endogenous levels of IAA, GA, ABA, and ZR by an indirect enzyme-linked immunosorbent assay (ELISA) technique were performed as described by He (1993). The samples were extracted with ice-cold $80 \%$ methanol $(\mathrm{v} / \mathrm{v})$ containing $1 \mathrm{~mm}$ butylated hydroxytoluene to prevent oxidation using a mortar and pestle and then stored overnight at $4{ }^{\circ} \mathrm{C}$. The extracts were collected after centrifugation at $12,000 g_{n}$ for $15 \mathrm{~min}$ at $4{ }^{\circ} \mathrm{C}$. The residues were suspended in the same ice-cold extraction solution and stored at $4^{\circ} \mathrm{C}$ for $1 \mathrm{~h}$, then centrifuged again at $12,000 \mathrm{~g}_{\mathrm{n}}$ for $15 \mathrm{~min}$ at $4{ }^{\circ} \mathrm{C}$. The two resulting supernatants were combined and passed through a $\mathrm{C}_{18}$ Sep-Pak cartridge (Waters, Milford, MA). The efflux was collected and dried in $\mathrm{N}_{2}$. The residues were then dissolved in $0.01 \mathrm{M}$ phosphate buffer solution $(\mathrm{pH} 7.4)$ to determine the levels of IAA, GAs, ABA, and ZR. In brief, microtitration plates (Nunc, Roskilde, Denmark) were coated with synthetic IAA, GAs, ABA, or ZR-ovalbumin conjugates in $50 \mathrm{~mm} \mathrm{NaHCO}_{3}$ buffer solution ( $\mathrm{pH}$ 9.6) and left overnight at $37{ }^{\circ} \mathrm{C}$. Ovalbumin solution $\left(10 \mathrm{mg} \cdot \mathrm{mL}^{-1}\right)$ was added to each well of the plates to block nonspecific binding. After incubation for $30 \mathrm{~min}$ at $37^{\circ} \mathrm{C}$, standard IAA, GAs, ZR, ABA, samples and antibodies were added and incubated for a further $45 \mathrm{~min}$ at $37^{\circ} \mathrm{C}$. Antibodies against IAA, GAs, ABA, and ZR were produced according to the method described by Weiler et al. (1981). Horseradish peroxidase-labeled goat antirabbit immunoglobulin was then added to each well and incubated for $1 \mathrm{~h}$ at $37^{\circ} \mathrm{C}$. After incubation, the buffered enzyme substrate solution (orthophenylenediamino) was added to each well of the plates. The plates were then kept in the dark at $37^{\circ} \mathrm{C}$ for the substrate reaction. After $15 \mathrm{~min}, 3 \mathrm{M} \mathrm{H}_{2} \mathrm{SO}_{4}$ was added to each well to end the substrate reaction. The absorbance was measured at $490 \mathrm{~nm}$ using the ELISA Recorder (model DG-3022 A; Huadong Electron Tube Factory, Shanghai, China). Calculations for the ELISA data were performed according to the method described by Weiler et al. (1981). In this study, the percentage recovery of each hormone was calculated by adding known quantities of standard hormone to a split extract. All the percentage recoveries were above $90 \%$, and all the sample extract dilution curves paralleled the standard curves, indicating the absence of nonspecific inhibitors in the extracts. The results are the means of six replicates.

Gene EXPRESSION ANALYSIS BY QRT-PCR. To assay the expression levels of mRNA of putative key genes associated with stolon formation in T. edulis, qRT-PCR was performed using ABI 7300 Real-Time PCR System (Applied Biosystems, Foster City, CA) with fluorescence dye SYBR Green (TaKaRa, Dalian, China). On the basis of the transcriptome sequencing and annotation, the putative unigenes involved in sucrose and starch metabolism were identified, and three essential genes were selected for verification: SS, SSSI, and SSSII (Z.B. Zhu, unpublished data). The gene-specific primers were designed by Primer Premier 5.0 (Premier Corp., Canada) and the primer sequences are listed in Table 1. The PCR conditions were as follows: $95^{\circ} \mathrm{C}$ for $30 \mathrm{~s}$; 40 cycles of $95^{\circ} \mathrm{C}$ for $5 \mathrm{~s}$ and $58{ }^{\circ} \mathrm{C}$ for $30 \mathrm{~s}$. Each reaction was repeated three times, and $\beta$-Actin was used as an internal control. The relative expression levels of the selected genes were calculated using the $2^{-\Delta \Delta C t}$

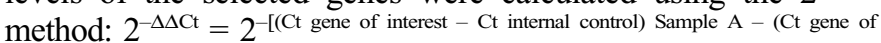
interest - Ct internal control) Sample B] (Zheng et al., 2014).

Statistical AnALYsis. The data presented in the figures were analyzed via one-way analysis of variance using SPSS Statistics 20.0 (IBM Corp., Armonk, NY), and significant differences in each index among the different development stages were determined using Duncan's multiple range test at a $0.05 P$ level. SPSS Statistics 20.0 was used to determine correlation coefficients.

\section{Results}

Content of TOtAl SOluble SUgAR, SUCROSE, REDUCing SUGAR, AND FRUCTOSE. We observed significant differences in total soluble sugar, sucrose, reducing sugar, and fructose content during the stolon formation of T. edulis (Fig. 2A).

Table 1 . Genes verified by quantitative real-time polymerase chain reaction (qRT-PCR) and primers used for qRT-PCR in stolons during Tulipa edulis stolon formation.

\begin{tabular}{lll}
\hline Gene & Primer name & \multicolumn{1}{c}{$5^{\prime}-3^{\prime}$} \\
\hline SS & c96901-F & TTGGTAACTTGGATGACCGA \\
& c96901-R & TTTGCCAGTTCTCTCAATCG \\
SSSI & c980201-F & TCTCGCAAGCTCCAGTACAA \\
& c980201-R & TGGAATTGAGCTCTTTCTCG \\
SSSII & c980202-F & CCTCCTTCGAGTATGTGGGT \\
& c980202-R & CGCTCGAGTTATCTTCACCA \\
$\beta$ - Actin & c92841-F & TGTATGTTGCCATTCAGGCT \\
& c92841-R & ATCACCAGAATCCAGCACAA \\
\hline
\end{tabular}




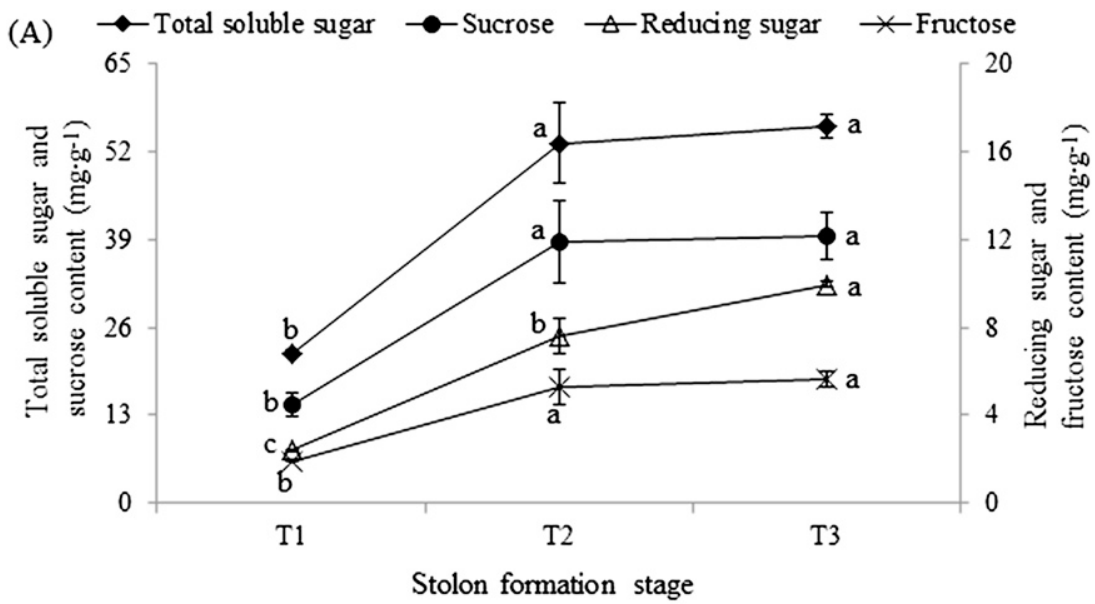

Activities of AGPase, SSS, ANd GBSS. The activity of AGPase increased gradually from $\mathrm{T} 1$ to $\mathrm{T} 2$, followed by a remarkable enhancement to a peak of 9.622 $\mu \mathrm{mol} \cdot \mathrm{g}^{-1} \cdot \mathrm{min}^{-1}$ in T3 (Fig. 3B). SSS activity increased rapidly initially, peaking in $\mathrm{T} 2$, and the activity was 2.124 times the level in T1. Then, it significantly decreased, with a decline of $32.35 \%$ in $\mathrm{T} 3$ compared with $\mathrm{T} 2$. The trends of GBSS and SSS activity were similar. GBSS activity was significantly increased by $208.80 \%$ in T2 compared with $\mathrm{T} 1$, then decreased in $\mathrm{T} 3$ but remained significantly higher than in $\mathrm{T} 1$.

CORRELATION ANALYSIS OF CARBOHYDRATE CONTENT AND CARBOHYDRATE-RELATED ENZYME ACTIVITIES. There were significant positive correlations among total soluble sugar, sucrose, reducing sugar, and fructose content, and the positive correlations of starch, total soluble sugar, sucrose, and fructose content were also significant (Table 2). SPS activity was negatively correlated with total soluble sugar, sucrose, reducing sugar, and fructose content. A similar result was observed for the correlation between SS activity and soluble sugars, but the relationship was not significant. AMY activity had a significant negative correlation with total soluble sugar, sucrose, reducing sugar, and fructose content and was weakly negatively related to starch content and to AGPase, SSS, and GBSS activities. In addition, positive correlations were found between starch content and starch synthetic enzyme activities, and the correlation between starch content and GBSS activity was significant.

GA, ABA, IAA, AND ZR CONTENT AND THE RATIOS OF ABA to IAA, GA, AND ZR.

The total soluble sugar, sucrose, and fructose content were all enhanced promptly in $\mathrm{T} 2$, showing increases of $139.14 \%$, $165.20 \%$, and $177.91 \%$ compared with $\mathrm{T} 1$, respectively, and then maintained a steady level until T3. The reducing sugar level increased continually throughout this period. The reducing sugar levels in T2 and T3 were 3.18- and 4.18-fold the value during $\mathrm{T} 1$, respectively.

Content OF STARCH AND PROTEIN. The starch content was significantly higher in $\mathrm{T} 2$ than in $\mathrm{T} 1$ (Fig. 2B) and subsequently decreased in T3 by $10.84 \%$ in comparison with $\mathrm{T} 2$, which was not statistically significant. The soluble protein content decreased continuously during stolon formation. It was highest in $\mathrm{T} 1$ and lowest in T3, and it was as much as two times at its peak as at its nadir. There was a significant decline in the content of nonsoluble protein during stolon formation (Fig. 2B).

ACTIVITIES OF SS, SPS, AND AMY. The activities of SS and SPS decreased significantly from T1 to T2 and then increased slowly (Fig. 3A). They both reached the minimum values in T2, $8.89 \%$ and $31.45 \%$ lower than in T1, respectively. Moreover, SPS activity was always lower than SS. The activity of AMY showed a significant decrease during stolon formation, and the activity during $\mathrm{T} 3$ was $31.58 \%$ of the activity in $\mathrm{T} 1$.
Figure 4A shows that the content of GA descends throughout, occurring at a higher level in T1, decreasing significantly in T2, and then being somewhat reduced in $\mathrm{T} 3$ but remaining fairly flat compared with the T2 stage and at $67.52 \%$ of the T1 stage. A similar result was observed for ZR content. The IAA content increased and peaked in $\mathrm{T} 2$ but showed no significant difference between T1 and T2. There was a sharp decrease in T3, with only $47.79 \%$ of the T2 content. The ABA content in T2 decreased slightly but maintained about the same level as in T1, reaching the value of $91.720 \mathrm{ng} \cdot \mathrm{g}^{-1}$, followed by a significant decrease during $\mathrm{T} 3$.

As shown in Figure 4B, the ABA:IAA ratio decreased steadily and achieved its lowest level during $\mathrm{T} 2$, and was then enhanced significantly in T3, showing an increase of $59.56 \%$ compared with the T2 period. No significant differences were found in the ratios of ABA:GA or ABA:ZR among the three stages during stolon formation.

EXPRESSION ANALYSIS OF SELECTED THREE GENES THROUGH QRT-PCR. From the qRT-PCR results (Fig. 5A), the gene expression level of $S S$ was down-regulated during stolon formation, and the expression level of the $S S$ gene was significantly higher in T1 than in T2 and T3. Conversely, the SSSI gene showed a significantly higher transcriptional level in 


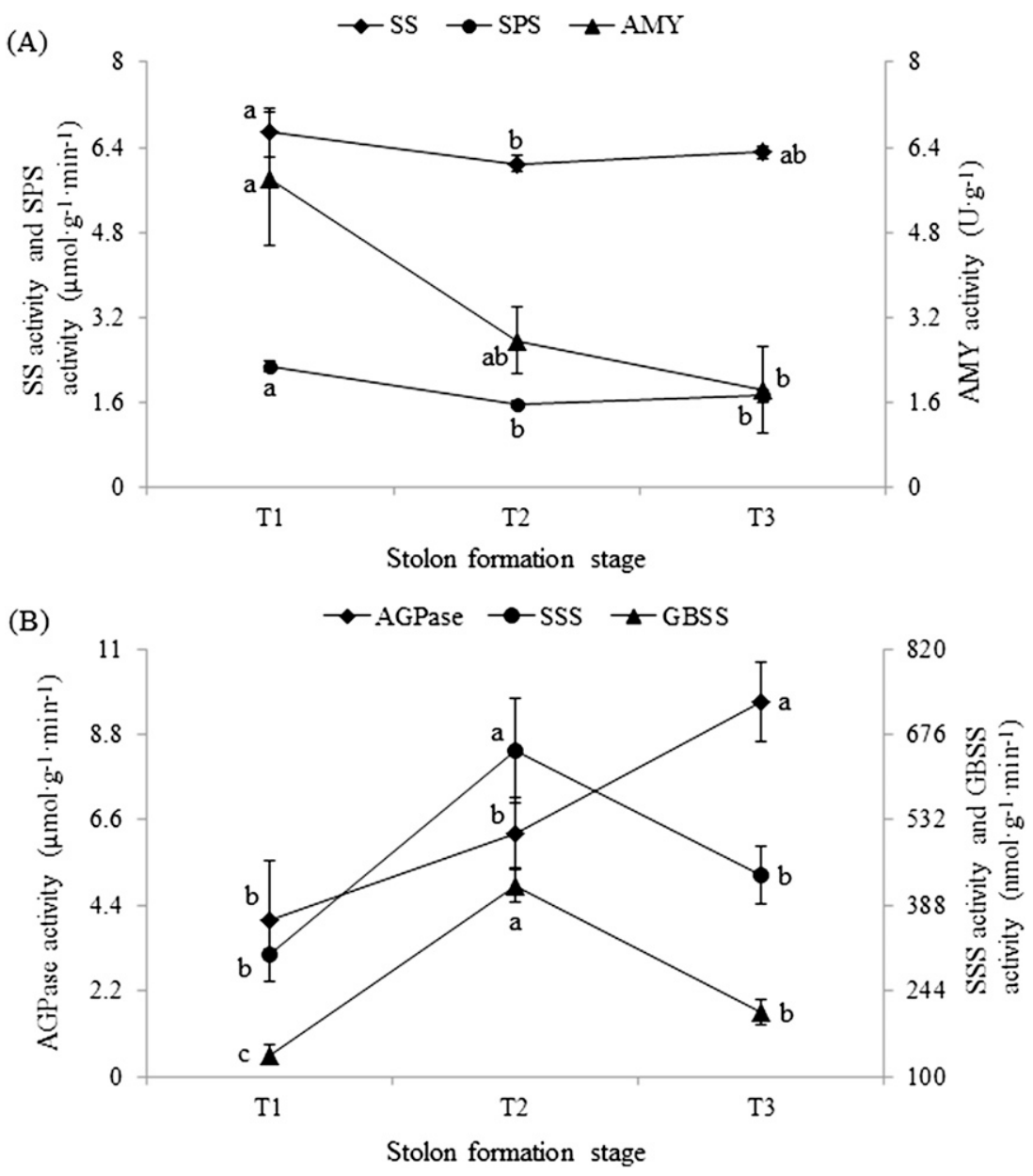

Fig. 3. Dynamic changes in (A) sucrose synthase (SS), sucrose phosphate synthase (SPS), and amylase (AMY) and (B) adenosine diphosphoglucose pyrophosphorylase (AGPase), soluble starch synthase (SSS), and granule-bound starch synthase (GBSS) activities in stolons during Tulipa edulis stolon formation. T1, T2, and T3 indicate the initial, middle, and later periods of stolon formation, respectively. Different lowercase letters in each index indicate significant differences (Duncan's multiple range test at $P<0.05$ ) among the three developmental stages. The error bars indicate SD of the three replicates.
$\mathrm{T} 3$ than $\mathrm{T} 1$ and $\mathrm{T} 2$, and the difference in the expression level of SSSI between T1 and T2 was not significant (Fig. 5B). Compared with T1, the SSSII gene expression level increased significantly, by $710.25 \%$ and $583.39 \%$, in $\mathrm{T} 2$ and $\mathrm{T} 3$, respectively. The analysis of the expression patterns of these genes was helpful to further understand the sucrose and starch metabolism during stolon formation.

\section{Discussion}

The formation of the stolon in T. edulis is similar to the formation of the stolon in potato in appearance. During stolon formation of $T$. edulis, meristematic cells in the specific tissue of the stem base generate a serial process of cell division and enlargement, and the tissue thereby bulges to form a stolon (Z.B. Zhu, unpublished data). The process of stolon formation is closely related to complex physiological changes such as the stolon in potato, involving many changes in nutrients, related enzyme activities, and endogenous hormone levels.

StOlOn FORMATION AND CHANGeS IN NUTRIENT CONTENT. Carbohydrates exist in the lily bulb as primary nutrients, not only as carbon frame providers of various types of chemicals but also as energy carriers required for substance synthesis, and play an important role in the growth, development, and physiological metabolism of the bulb ( $\mathrm{Li}$ et al., 2014). Soluble sugars, mainly sucrose and reducing sugar, are the chief nutrients and carbon sources and can be directly used and transported in the bulb. Our work

Table 2. Correlation analysis of carbohydrate content and carbohydrate-related enzyme activities in stolons during Tulipa edulis stolon formation.

\begin{tabular}{|c|c|c|c|c|c|c|c|c|c|c|c|}
\hline & $\begin{array}{l}\text { Total soluble } \\
\text { sugar }\end{array}$ & Sucrose & $\begin{array}{l}\text { Reducing } \\
\text { sugar }\end{array}$ & Fructose & Starch & $\mathrm{SS}^{\mathrm{z}}$ & SPS & AMY & AGPase & SSS & GBSS \\
\hline $\begin{array}{l}\text { Total soluble } \\
\text { sugar }\end{array}$ & 1 & & & & & & & & & & \\
\hline Reducing sugar & $0.879 * *$ & $0.890 * *$ & 1 & & & & & & & & \\
\hline Fructose & $0.985 * *$ & $0.984 * *$ & $0.914 * *$ & 1 & & & & & & & \\
\hline Starch & $0.766^{*}$ & $0.740^{*}$ & 0.468 & $0.751 *$ & 1 & & & & & & \\
\hline SPS & $-0.855^{* *}$ & $-0.882 * *$ & $-0.837 * *$ & $-0.871 * *$ & -0.594 & 0.598 & 1 & & & & \\
\hline AMY & $-0.674^{*}$ & $-0.744 *$ & $-0.810^{* *}$ & $-0.743^{*}$ & -0.260 & 0.333 & $0.701 *$ & 1 & & & \\
\hline AGPase & $0.761^{*}$ & $0.725^{*}$ & $0.849 * *$ & $0.778^{*}$ & 0.295 & -0.417 & -0.585 & -0.610 & 1 & & \\
\hline SSS & 0.525 & 0.580 & 0.528 & 0.575 & 0.566 & $-0.710 *$ & $-0.739 *$ & -0.550 & 0.092 & 1 & \\
\hline GBSS & 0.640 & $0.670^{*}$ & 0.423 & 0.630 & $0.745^{*}$ & -0.660 & $-0.791 *$ & -0.360 & 0.118 & $0.816^{*}$ & 1 \\
\hline
\end{tabular}

${ }^{\mathrm{z}} \mathrm{SS}=$ sucrose synthase; $\mathrm{SPS}=$ sucrose phosphate synthase; AMY = amylase; AGPase $=$ adenosine diphosphoglucose pyrophosphorylase; SSS = soluble starch synthase; GBSS = granule-bound starch synthase.

*The level of significance (Pearson product-moment correlation) is $0.01<P<0.05$.

**The level of significance (Pearson product-moment correlation) is $P<0.01$. 


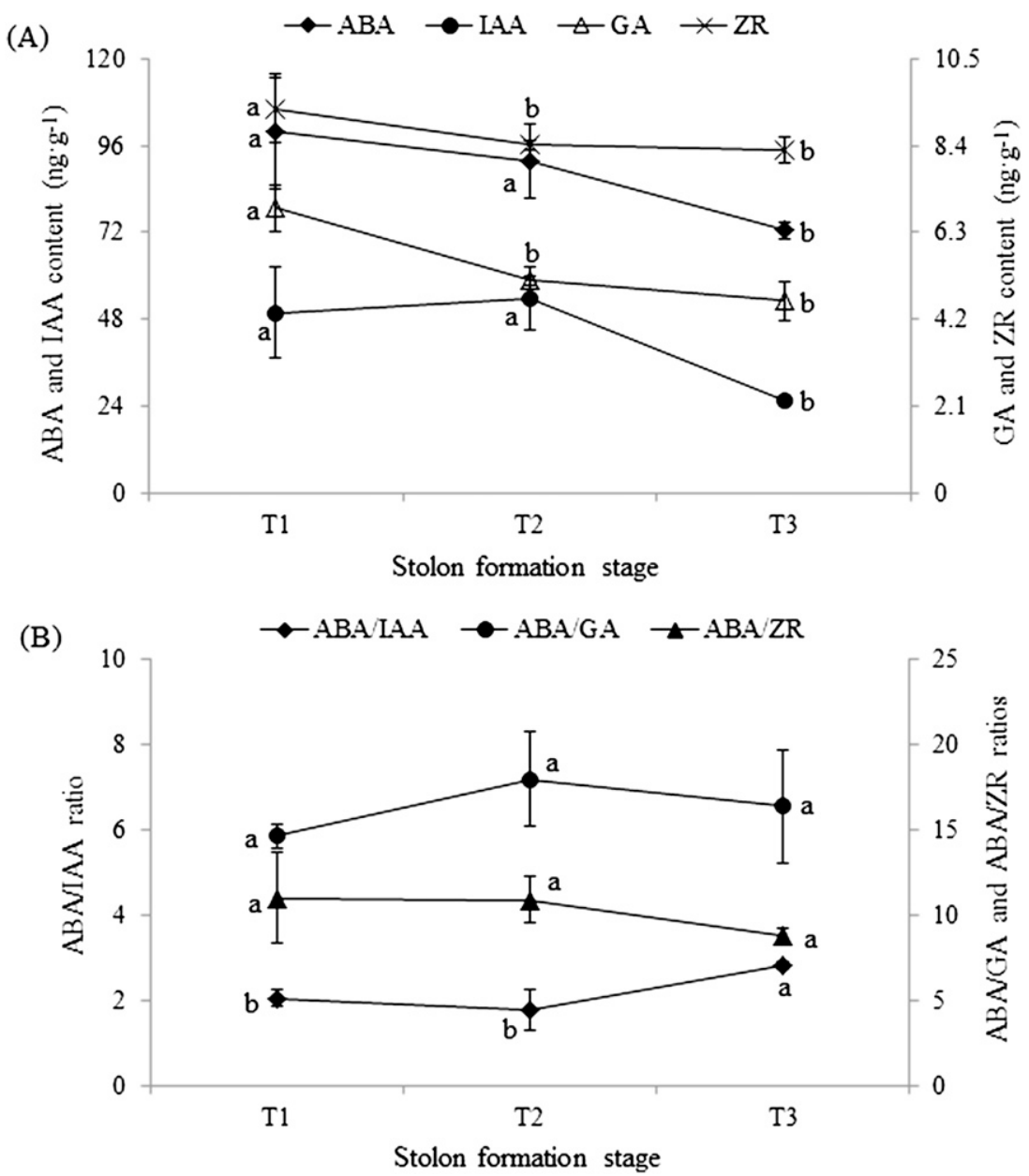

Fig. 4. Dynamic changes in (A) abscisic acid (ABA), indole-3-acetic acid (IAA), gibberellin (GA), and zeatin riboside $(\mathrm{ZR})$ content and $(\mathbf{B})$ the ratios of ABA:IAA, ABA:GA, and ABA:ZR in stolons during Tulipa edulis stolon formation. T1, T2, and T3 indicate the initial, middle, and later periods of stolon formation, respectively. Different lowercase letters in each index indicate significant differences (Duncan's multiple range test at $P<0.05$ ) among the three developmental stages. The error bars indicate SD of the six replicates.

demonstrated that the total soluble sugar content was significantly increased in the middle period compared with the initial period of stolon formation (Fig. 2A). A likely explanation is that during the middle period in stolon formation, cells are highly active, accompanied by a great deal of cell division and cell enlargement, and that the accumulation of total soluble sugar could supply the nutrients and energy (Simard et al., 2013) for stolon organogenesis. The stolon still maintained a relatively high level of total soluble sugar during the later period, which was consumed less and amassed for further stolon development. As shown in Figure 2A, the ratio of sucrose to total soluble sugar can reach up to values ranging from $65.54 \%$ to $72.68 \%$, and the changing trend of sucrose was consistent with the trend of total soluble sugar. A similar phenomenon was reported in lily bulbs by Shin et al. (2002) and Sun et al. (2005), supporting the idea that sucrose is the major form of total soluble sugar in long-distance transportation for direct participation in stolon formation in T. edulis. Reducing sugar content, including primarily fructose and glucose, was relatively lower than that of sucrose but showed a significant difference during stolon formation (Fig. 2A). It is inferred that the change in reducing sugar embodies the supply and transformation of carbohydrates in stolon formation, as found by Sun et al. (2005) in lily, and the increase in reducing sugar when the stolon emerges coincides with the high metabolic activity of the dividing and rapidly growing cells (Simard et al., 2013). In addition, sucrose and reducing sugar typically act as a signaling molecule in plant development, so the specific mechanism of sucrose and reducing sugar in regulating stolon emergence by inducing the expression of related genes requires further investigation.

Starch is the main storage form of carbohydrates and also an important energy source in the bulb, and its metabolic characteristics are among the critical factors affecting organogenesis in plants (Qu et al., 1998). The results of the current study showed that starch content accumulated during the middle period when stolon emerged, in accord with the study in the haustorial development of Santalum album (Zhang et al., 2012), supporting the view that soluble sugar in the mother bulb was transported to the specific site of the stem for starch synthesis to satisfy the reserve substance and energy demands of active cells, including cell division and differentiation, during stolon morphogenesis. This result illustrated that starch accumulation was likely preparation for the initiation of new plant organs through substance and energy supplies or that it indicated an upcoming new developmental status in plants, such as organogenesis, in accordance with the viewpoint presented by Thorpe and Murashige (1968). In short, the starch and soluble sugars accumulation during the middle period, combined with their positive correlations (Table 2), suggested that the stolon developed in a stage of high levels of carbohydrate. This result was consistent with the previous observations that starch and soluble sugar contents increased together in daughterbulb formation in lily and tuber initiation in potato (Fernie and Willmitzer, 2001; Xia et al., 2005). Protein is a vital nutrient and closely related to carbohydrate, and the two can be interconverted (Ribeiro et al., 2014). Therefore, the decrease in soluble protein content during stolon formation might be used to generate nutrient and energy sources to meet the requirements of the transportation and accumulation of carbohydrates as well as the increased cell number and cell volume in the stolon.

STOLON FORMATION AND SUCROSE AND STARCH METABOLISM. Sucrose and starch metabolism have provided a breakthrough for researching organogenesis via the close interaction between sucrose, starch and their related metabolic enzymes, which has been applied to other plants to study tuber and bulblet formation thoroughly and systemically (Li et al., 2014; Li and Zhang, 2003). In this work, we also discussed how sucrose and starch metabolism-related enzymes influence stolon formation with soluble sugars and starch. SPS and AMY activities peaked in the initial period of stolon formation (Fig. 3A). Once stolon 

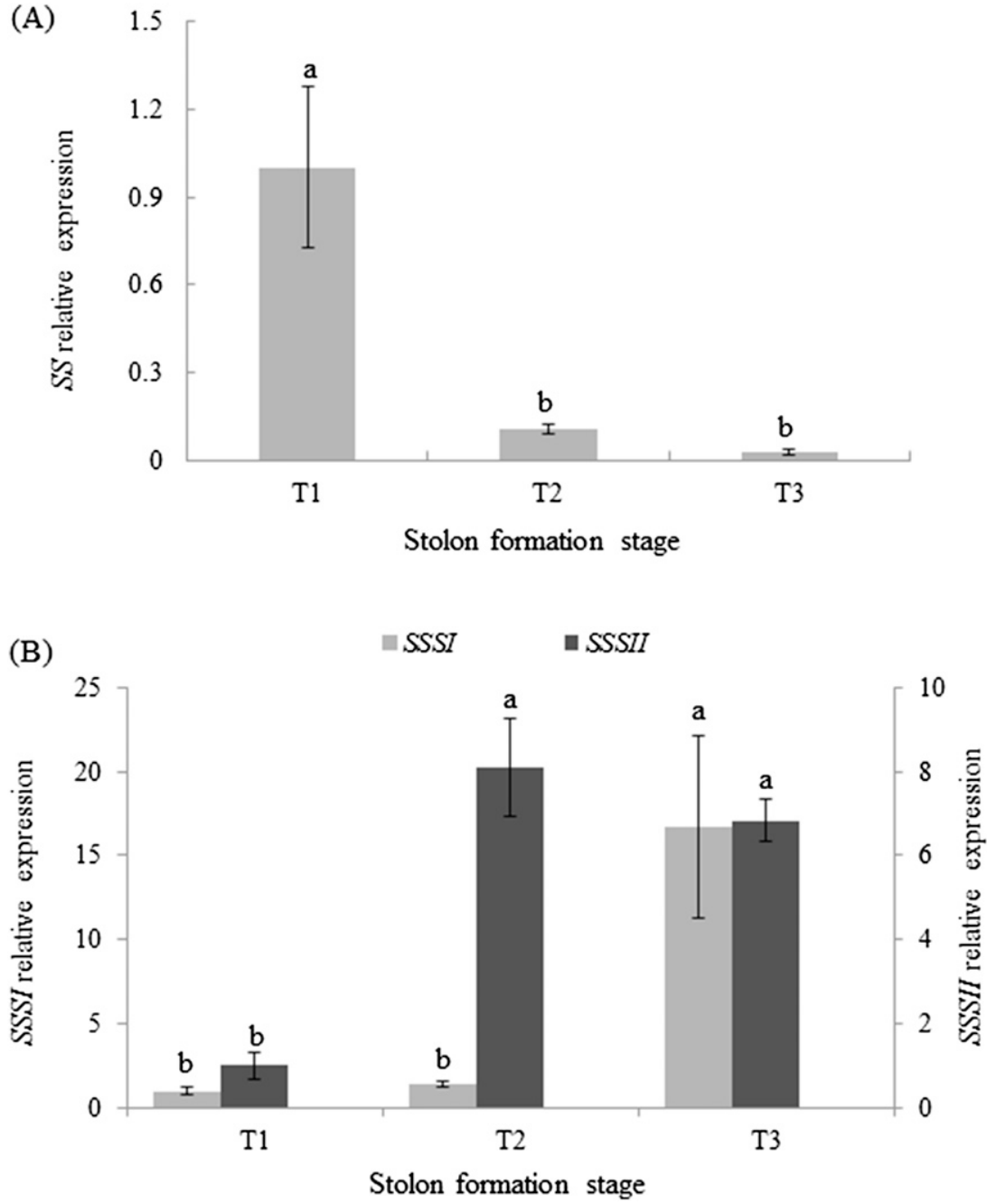

Fig. 5. Validation of selected three sucrose--starch metabolism-related genes (A) SS (sucrose synthase and (B) SSS (soluble starch synthase) from three developmental stages in stolons during stolon formation of Tulipa edulis with quantitative real-time PCR (qRT-PCR). T1, T2, and T3 indicate the initial, middle, and later periods of stolon formation, respectively. Different lowercase letters indicate significant differences (Duncan's multiple range test at $P<0.05$ ) among the three developmental stages. The error bars indicate SD of the three replicates.

morphology was established, SPS and AMY participated immediately in material transformation and thereby offered energy for cell division and growth. Previous research demonstrated that SPS was an important enzyme in SS, and sucrose was positively related to SPS activity (Shin et al., 2002), in contrast to our results. The peak of SPS activity was achieved in the initial period and appeared to be backward to some degree; in the middle period, transforming reducing sugar transited from the mother bulb into sucrose (Huber and Huber, 1996), so the result assumed that sucrose content was significantly increased at the middle stage compared with the initial stage. However, sucrose might have an impact on the activities of sucrose-metabolizing enzymes through feedback adjustment, as sucrose was a metabolism regulatory factor (Chen et al., 2000; Koch, 1996), producing a balanced relationship between sucrose and SPS. Specifically, a high level of sucrose might inhibit the rise of SPS activity, while the reduction in SPS activity in turn might weaken the synthetic ability to turn reducing sugar into sucrose. However, the sucrose content did not decline because sucrose was transited constantly from the mother bulb to the stolon for rapid replenishment. The above hypothesis would explain the significant increase in sucrose content in the middle period and its stabilization at a high level in the later period compared with the initial period of stolon formation. AMY attained its maximum activity in the initial period and promoted starch degradation to produce reducing sugar (Mishra and Dubey, 2013) for stolon emergence in the middle period, with the same performance lag as SPS. Combined with the reducing sugar transported continually from the mother bulb, reducing sugar content rose increasingly and hence showed a significantly negative correlation with AMY activity during stolon formation (Table 2).

Starch metabolism is a common dynamic process of starch synthesis and degradation. On the basis of the changes of starch content and AMY, AGPase, SSS, and GBSS activities and their correlations, starch synthesis played the leading role in starch metabolism, resulting in a condition of gradual starch accumulation. In the process of starch synthesis, sucrose served as the basic metabolic substance and was transported in the phloem over long distances and downloaded to the stolon location, becoming available for starch synthesis through metabolic process (Bánfalvi et al., 1996). In addition, SS is an exclusive necessary enzyme to prompt sucrose into the pathway of the sucrose-starch metabolism (Sung et al., 1989), and the inverse correlation relationship between sucrose content and SS activity suggests that the dominant role of the decomposition of $\mathrm{SS}$ in sucrose. In this study, the activity of SS peaked in the initial period of stolon formation, and it was confirmed by qRT-PCR approach that the $S S$ gene was active at the initial stage but rapidly down-regulated to a low level in the middle and later period of stolon formation (Fig. 5A). Therefore, the high level of SS activity in the initial period was beneficial for rapidly digesting sucrose into fructose and UDPG, not only providing a great driving force for cell growth by increasing cell osmotic pressure for stolon emergence in the middle period, but also generating a sucrose concentration gradient to facilitate the phloem loading and unloading of sucrose beneficial for continued stolon growth and for generating the preconditions (fructose, UDPG) of starch synthesis (Rouhier and Usuda, 2001; Wang et al., 1999). Fructose and UDPG were converted to glucose-1-phosphate or glucose-6-phosphate with a series of catalytic reactions (Fernie et al., 2002). In the present study, the gradual increase in AGPase activity as stolon formation progressed catalyzed the reaction between glucose-1-phosphate or glucose-6-phosphate and adenosine triphosphate to generate substantial amounts of precursor ADPG for starch synthesis. Following the production of ADPG as a substrate, starch synthesis proceeded via the catalytic reaction of SSS and GBSS (Mukerjea et al., 2010). 
Therefore, the peak in starch content during the middle period resulted from the highest activities of SSS and GBSS compared with the other two periods and significant correlation between GBSS activity and starch content. The qRTPCR results also confirmed this analysis by showing that the SSSII gene was up-regulated in the middle period compared with the initial and later period of stolon formation (Fig. 5B). However, SSSI gene expression was observed to show some differences in transcriptional level compared with the SSSII gene. It is possible that SSSI and SSSII are two key genes encoding SSS, playing different roles in different stages during stolon formation. The qRT-PCR results for SSSI and SSSII as a whole verified the change in SSS activity resulting from their high expression levels at the middle and later stage of stolon formation.

STOLON FORMATION AND CHANGES IN ENDOGENOUS HORMONES. Coinciding with changes in ZR content, GA content reached its highest value in the initial period and then declined during stolon formation. It may be because GA and ZR play dominant roles in stimulating cell division and elongation growth (Chope et al., 2012) during the initial period of stolon formation. As the peak GA and ZR levels in the initial period were accompanied by higher IAA content, it might be suggested that GA, ZR, and IAA were working more efficiently to prepare cell activities for stolon emergence. Previous researches reported that IAA was benefit for cell growth (Roumeliotis et al., 2012) and starch synthesizing metabolism (Borzenkova et al., 1998). Therefore, in the middle period, the IAA content peaked to prompt cell division, elongation and expansion, and simultaneously stimulates starch synthesis and assimilates translocation, triggering the initiation of the stolon in the middle period (Fig. 1D). This result was closely consistent with previous works in lily and tulip bulb formation (Podwyszyńska, 2006; Zheng et al., 2012). Nevertheless, there were drastic decreases in the GA, IAA, and ZR content in the later period, which demonstrated that cell growth became slow, and reserve materials were largely accumulated to enrich and fill the stolon after stolon emergence. A high concentration of $\mathrm{ABA}$ was previously considered to hamper tarda tulip bulblet formation (Maślanka and Bach, 2014), while the ABA level was relatively high when the stolon emerged in our study. Thus, there seems to be a balance of hormones, especially the ratio of ABA:IAA, which was significantly lower in the initial and middle period compared with the later period of stolon formation (Fig. 4B), suggesting that IAA played a stimulatory role in stolon formation via the suppression of ABA. It was concluded that the hormones synthesized in T. edulis stolon is apparently necessary for cell division and growth of the meristematic regions during stolon development.

\section{Conclusions}

Stolon emergence was indicated by the simultaneous accumulation of soluble sugars (sucrose, reducing sugar, and fructose) and starch, which was the cumulative effect of many enzymes. The endogenous level of IAA showed a positive regulation in stolon emergence. The highest content of IAA and lowest ratio of ABA:IAA were detected in the middle period of stolon formation, i.e., in stolon emergence. We report for the first time on the carbohydrate and endogenous hormones roles in stolon formation, which benefit for further regulation in T. edulis stolon growth.

\section{Literature Cited}

Agulló-Antón, M.Á., A. Ferrández-Ayela, N. Fernández-García, C. Nicolás, A. Albacete, F. Pérez-Alfocea, J. Sánchez-Bravo, J.M. Pérez-Pérez, and M. Acosta. 2014. Early steps of adventitious rooting: Morphology, hormonal profiling and carbohydrate turnover in carnation stem cuttings. Physiol. Plant. 150:446-462.

Ahkami, A.H., S. Lischewski, K.T. Haensch, S. Porfirova, J. Hofmann, H. Rolletschek, M. Melzer, P. Franken, B. Hause, U. Druege, and M.R. Hajirezaei. 2009. Molecular physiology of adventitious root formation in Petunia hybrida cuttings: Involvement of wound response and primary metabolism. New Phytol. 181:613-625.

Bakhshaie, M., M. Babalar, M. Mirmasoumi, and A. Khalighi. 2010. Somatic embryogenesis and plant regeneration of Lilium ledebourii (Baker) Boiss., an endangered species. Plant Cell Tissue Organ Cult. 102:229-235.

Bánfalvi, Z., A. Molnár, G. Molnár, L. Lakatos, and L. Szabó. 1996. Starch synthesis, and tuber storage protein genes are differently expressed in Solanum tuberosum and in Solanum brevidens. FEBS Lett. 383:159-164.

Baroja-Fernández, E., F.J. Muñoz, M. Montero, E. Etxeberria, M.T. Sesma, M. Ovecka, A. Bahaji, I. Ezquer, J. Li, S. Prat, and J. PozuetaRomero. 2009. Enhancing sucrose synthase activity in transgenic potato (Solanum tuberosum L.) tubers results in increased levels of starch, ADPglucose and UDPglucose and total yield. Plant Cell Physiol. 50:1651-1662.

Baroja-Fernández, E., F.J. Muñoz, T. Saikusa, M. Rodríguez-López, T. Akazawa, and J. Pozueta-Romero. 2003. Sucrose synthase catalyzes the de novo production of ADPglucose linked to starch biosynthesis in heterotrophic tissues of plants. Plant Cell Physiol. 44:500-509.

Bielach, A., K. Podlesáková, P. Marhavy, J. Duclercq, C. Cuesta, B. Müller, W. Grunewald, P. Tarkowski, and E. Benková. 2012. Spatiotemporal regulation of lateral root organogenesis in Arabidopsis by cytokinin. Plant Cell 24:3967-3981.

Bing, Q.Z., B.G. Zhang, Z. Zhang, and Z.H. Chen. 2008. Study on good agricultural practice for Tulipa edulis-Planting density and sowing depth tests. Zhongguo Zhong Yao Za Zhi 33:2463-2466.

Borzenkova, R.A., E.A. Sobyanina, A.A. Pozdeeva, and M.Y. Yashkov. 1998. Effect of phytohormones on starch synthesizing capacity in growing potato tubers. Russ. J. Plant Physiol. 45:472-480.

Bradford, M.M. 1976. A rapid and senstitive method for the quantication of microgram quantities of protein by utilizing the principle of protein-dye binding. Anal. Biochem. 72:248-254.

Chen, J.W., L.C. Zhang, and S.L. Zhang. 2000. Sugar accumulation mechanism in fruits. Plant Physiol. Commun. 36:497-503.

Cheng, L., S. Li, X. Xu, J. Hussain, J. Yin, Y. Zhang, L. Li, and X. Chen. 2013b. Identification of differentially expressed genes relevant to corm formation in Sagittaria trifolia. PLoS One 8:e54573.

Cheng, L., S. Li, J. Yin, L. Li, and X. Chen. 2013a. Genome-wide analysis of differentially expressed genes relevant to rhizome formation in lotus root (Nelumbo nucifera Gaertn). PLoS One 8: e67116.

Chinese Herbalism Editorial Board. 1999. Chinese Materia Medica. Shanghai Sci. Technol. Press, Shanghai, China.

Chope, G.A., K. Cools, J.P. Hammond, A.J. Thompson, and L.A. Terry. 2012. Physiological, biochemical and transcriptional analysis of onion bulbs during storage. Ann. Bot. 109:819-831.

Chow, Y.N., C. Selby, and B.M.R. Harvey. 1992. Stimulation by sucrose of Narcissus bulbil formation in vitro. J. Hort. Sci. 67:289293.

Custers, J.B.M., W. Eikelboom, J.H.W. Bergervoet, and J.P. van Eijk. 1992. In ovulo embryo culture of tulip (Tulipa L.): Effects of culture conditions on seedling and bulblet formation. Sci. Hort. 51:111-122. da Costa, C.T., M.R. de Almeida, C.M. Ruedell, J. Schwambach, F.S. Maraschin, and A.G. Fett-Neto. 2013. When stress and development go hand in hand: Main hormonal controls of adventitious rooting in cuttings. Front. Plant Sci. 4:133. 
Della Rovere, F., L. Fattorini, S. D’Angeli, A. Veloccia, G. Falasca, and M.M. Altamura. 2013. Auxin and cytokinin control formation of the quiescent centre in the adventitious root apex of arabidopsis. Ann. Bot. 112:1395-1407.

El Grari, R. and R.A. Backhaus. 1987. In vitro propagation of red squill, Urginea maritima Baker. Plant Cell Tissue Organ Cult. 10:65-71.

Fernie, A.R. and L. Willmitzer. 2001. Molecular and biochemical triggers of potato tuber development. Plant Physiol. 127:1459-1465.

Fernie, A.R., L. Willmitzer, and R.N. Trethewey. 2002. Sucrose to starch: A transition in molecular plant physiology. Trends Plant Sci. 7:35-41.

Gauci, R., B. Otrysko, J.G. Catford, and L. Lapointe. 2009. Carbon allocation during fruiting in Rubus chamaemorus. Ann. Bot. 104:703-713.

Geigenberger, P. 2003. Regulation of sucrose to starch conversion in growing potato tubers. J. Expt. Bot. 54:457-465.

Guo, D., J. Liang, Y. Qiao, Y. Yan, L. Li, and Y. Dai. 2012. Involvement of G1-to-S transition and AhAUX-dependent auxin transport in abscisic acid-induced inhibition of lateral root primodia initiation in Arachis hypogaea L. J. Plant Physiol. 169:1102-1111.

He, Z. 1993. A laboratory guide to chemical control technology on field crop. Beijing Agr. Univ. Press, Beijing, China.

Hu, F., D. Wang, X. Zhao, T. Zhang, H. Sun, L. Zhu, F. Zhang, L. Li, Q. Li, D. Tao, B. Fu, and Z. Li. 2011. Identification of rhizomespecific genes by genome-wide differential expression analysis in Oryza longistaminata. BMC Plant Biol. 11:18.

Huber, S.C. and J.L. Huber. 1996. Role and regulation of sucrosephosphate synthase in higher plants. Annu. Rev. Plant Biol. 47:431444.

Ivanchenko, M.G., G.K. Muday, and J.G. Dubrovsky. 2008. Ethyleneauxin interactions regulate lateral root initiation and emergence in Arabidopsis thaliana. Plant J. 55:335-347.

Jackson, S.D. 1999. Multiple signaling pathways control tuber induction in potato. Plant Physiol. 119:1-8.

Klopotek, Y., K.T. Haensch, B. Hause, M.R. Hajirezaei, and U. Druege. 2010. Dark exposure of petunia cuttings strongly improves adventitious root formation and enhances carbohydrate availability during rooting in the light. J. Plant Physiol. 167:547-554.

Koch, K.E. 1996. Carbohydrate-modulated gene expression in plants. Annu. Rev. Plant Biol. 47:509-540.

Koster, J. 1993. In vitro propagation of tulip. MS Thesis, Univ. Leiden, The Netherlands.

Le Nard, M. and A. De Hertogh. 1993. Tulipa, p. 617-683. In: A. De Hertogh (ed.). The physiology of flower bulbs. Elsevier, Amsterdam, The Netherlands.

Li, K., H. Okubo, and T. Matsumoto. 2002. Control of bulb dormancy in hyacinth-A molecular biological approach. Acta Hort. 570:241245.

Li, X., C. Wang, J. Cheng, J. Zhang, J.A. da Silva, X. Liu, X. Duan, T. $\mathrm{Li}$, and H. Sun. 2014. Transcriptome analysis of carbohydrate metabolism during bulblet formation and development in Lilium davidii var. unicolor. BMC Plant Biol. 14:358.

Li, X.Q. and D. Zhang. 2003. Gene expression activity and pathway selection for sucrose metabolism in developing storage root of sweet potato. Plant Cell Physiol. 44:630-636.

Macgregor, D.R., K.I. Deak, P.A. Ingram, and J.E. Malamy. 2008. Root system architecture in Arabidopsis grown in culture is regulated by sucrose uptake in the aerial tissues. Plant Cell 20:2643-2660.

Maślanka, M. and A. Bach. 2014. Induction of bulb organogenesis in in vitro cultures of tarda tulip (Tulipa tarda Stapf.) from seed-derived explants. In Vitro Cell. Dev. Biol. Plant 50:712-721.

Mcintyre, G.I. 2001. Control of plant development by limiting factors: A nutritional perspective. Physiol. Plant. 113:165-175.

Miao, Y.Y., Z.B. Zhu, Q.S. Guo, H.L. Ma, and L.F. Zhu. 2015. Alternate wetting and drying irrigation-mediated changes in the growth, photosynthesis and yield of the medicinal plant Tulipa edulis. Ind. Crops Prod. 66:81-88.
Mishra, P. and R.S. Dubey. 2013. Excess nickel modulates activities of carbohydrate metabolizing enzymes and induces accumulation of sugars by upregulating acid invertase and sucrose synthase in rice seedlings. Biometals 26:97-111.

Mitprasat, M., S. Roytrakul, S. Jiemsup, O. Boonseng, and K. Yokthongwattana. 2011. Leaf proteomic analysis in cassava (Manihot esculenta, Crantz) during plant development, from planting of stem cutting to storage root formation. Planta 233:1209-1221.

Mukerjea, R., D.J. Falconer, S.H. Yoon, and J.F. Robyt. 2010. Largescale isolation, fractionation, and purification of soluble starchsynthesizing enzymes: Starch synthase and branching enzyme from potato tubers. Carbohydr. Res. 345:1555-1563.

Nakamura, Y., K. Yuki, and S.Y. Park. 1989. Carbohydrate metabolism in the developing endosperm of rice grains. Plant Cell Physiol. 30:833-839.

Podwyszyńska, M. 2006. Improvement of bulb formation in micropropagated tulips by treatment with NAA and paclobutrazol or ancymidol. In V Intl. Symp. In Vitro Cult. Hort. Breeding 725:679-684.

Podwyszyńska, M. and H. Ross. 2003. Formation of tulip bulbs in vitro. Acta Hort. 616:413-419.

Ptak, A. 2014. Leucojum aestivum L. in vitro bulbs induction and acclimatization. Open Life Sci. 9:1011-1021.

Qu, S., X. Liu, P. Zhou, X. Lu, and Z. Luo. 1998. Studies on the changes and comparison of physiology and biochemistry in the morphogenesis of scale explant of lily in vitro. Life Sci. Res. 2:288-294.

Rapaka, V.K., B. Bessler, M. Schreiner, and U. Druege. 2005. Interplay between initial carbohydrate availability, current photosynthesis, and adventitious root formation in Pelargonium cuttings. Plant Sci. 168:1547-1560.

Ribeiro, P.R., L.G. Fernandez, R.D.D. Castro, W. Ligterink, and H.W. Hilhorst. 2014. Physiological and biochemical responses of Ricinus communis seedlings to different temperatures: A metabolomics approach. BMC Plant Biol. 14:223.

Rice, R.D., P.G. Alderson, and N.A. Wright. 1983. Induction of bulbing of tulip shoots in vitro. Sci. Hort. 20:377-390.

Rouhier, H. and H. Usuda. 2001. Spatial and temporal distribution of sucrose synthase in the radish hypocotyls in relation to thickening growth. Plant Cell Physiol. 42:583-593.

Roumeliotis, E., B. Kloosterman, M. Oortwijn, W. Kohlen, H.J. Bouwmeester, R.G. Visser, and C.W. Bachem. 2012. The effects of auxin and strigolactones on tuber initiation and stolon architecture in potato. J. Expt. Bot. 63:4539-4547.

Schreiber, L., A.C. Nader-Nieto, E.M. Schönhals, B. Walkemeier, and C. Gebhardt. 2014. SNPs in genes functional in starch-sugar interconversion associate with natural variation of tuber starch and sugar content of potato (Solanum tuberosum L.). G3 Genes Genomes Genet. 4:1797-1811.

Shin, K.S., D. Chkerabarty, and K.Y. Paek. 2002. Sprouting rate, changes of carbohydrate contents and related enzymes during cold treatment of lily bulblets regenerated in vitro. Sci. Hort. 96:195-204. Simard, S., A. Giovannelli, K. Treydte, M.L. Traversi, G.M. King, D. Frank, and P. Fonti. 2013. Intra-annual dynamics of non-structural carbohydrates in the cambium of mature conifer trees reflects radial growth demands. Tree Physiol. 33:913-923.

Sinnott, E.W. 1960. Plant morphogenesis. McGraw-Hill, New York, NY.

Sun, H.M., T.L. Li, and Y.F. Li. 2005. Changes of carbohydrate and amylase in lily bulb during bulb development. Bull. Bot. Res. 25:59-63.

Sung, S.J., D.P. Xu, and C.C. Black. 1989. Identification of actively filling sucrose sinks. Plant Physiol. 89:1117-1121.

Takahashi, F., K. Sato-Nara, K. Kobayashi, M. Suzuki, and H. Suzuki. 2003. Sugar-induced adventitious roots in Arabidopsis seedlings. J. Plant Res. 116:83-91.

Thorpe, T.A. and T. Murashige. 1968. Starch accumulation in shoot forming tobacco callus cultures. Science 160:421-442.

Uranbey, S., A. Ipek, M. Caliskan, E. Dundar, S. Cocu, D. Basalma, and H. Guneylioglu. 2010. In vitro bulblet induction from bulb scales 
of endangered ornamental plant Muscari azureum. Biotechnol. Biotechnol. Equip. 24:1843-1848.

Van Aartrijk, J. and G.J. Blom-Barnhoorn. 1981. Growth regulator requirements for adventitious regeneration from Lilium bulb-scale tissue in vitro, in relation to duration of bulb storage and cultivar. Sci. Hort. 14:261-268.

Verma, A.K., A.K. Agarwal, R.S. Dubey, S. Solomon, and S.B. Singh. 2012. Sugar partitioning in sprouting lateral bud and shoot development of sugarcane. Plant Physiol. Biochem. 62:111-115.

Wang, F., A.G. Smith, and M.L. Brenner. 1999. Temporal and spatial expression pattern of sucrose synthase during tomato fruit development. Plant Physiol. 104:535-540.

Weiler, E.W., P.S. Jourdan, and W. Conrad. 1981. Levels of indole-3acetic acid in intact and decapitated coleoptiles as determined by a specific and highly sensitive solid-phase enzyme immunoassay. Planta 153:561-571.

Xia, Y.P., H.J. Zheng, and C.H. Huang. 2005. Studies on the bulb development and its physiological mechanisms in Lilium oriental hybrids. Acta Hort. 673:91-98.
Xu, X., A.A.M. van Lammeren, E. Vermeer, and D. Vreugdenhil. 1998b. The role of gibberellin, abscisic acid, and sucrose in the regulation of potato tuber formation in vitro. Plant Physiol. 117:575-584.

Xu, X., D. Vreugdenhil, and A.A.M. van Lammeren. 1998a. Cell division and cell enlargement during potato tuber formation. J. Expt. Bot. 49:573-582.

Zhang, X., J.A. Teixeira da Silva, J. Duan, R. Deng, X. Xu, and G. Ma. 2012. Endogenous hormone levels and anatomical characters of haustoria in Santalum album L. seedlings before and after attachment to the host. J. Plant Physiol. 169:859-866.

Zheng, K.Y., G.H. Zhang, N.H. Jiang, S.C. Yang, C. Li, Z.G. Meng, Q.S. Guo, and G.Q. Long. 2014. Analysis of the transcriptome of Marsdenia tenacissima discovers putative polyoxypregnane glycoside biosynthetic genes and genetic markers. Genomics 104:186-193.

Zheng, R.R., Y. Wu, and Y.P. Xia. 2012. Chlorocholine chloride and paclobutrazol treatments promote carbohydrate accumulation in bulbs of Lilium oriental hybrids 'Sorbonne'. J. Zhejiang Univ. Sci. B 13:136-144. 